\title{
Ethnographies of Volunteering: Providing Nuance to the Links Between Volunteering and Development
}

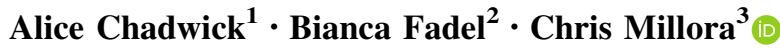

Accepted: 3 August 2021/Published online: 17 August 2021

(C) The Author(s) 2021

\begin{abstract}
This paper explores how ethnographic approaches to third sector and nonprofit studies allow for contextbased understandings of the links between volunteering and development. Drawing from our ethnographies of volunteering in Sierra Leone, Burundi and the Philippines, we argue that ethnographic methods could tease out local ideologies and practices of volunteer work that can challenge knowledge monopolies over how volunteering is understood and, later, transcribed into development policy and practice at various levels. The contribution of ethnography as a methodology to third sector research lies not only in the in-depth data it generates but also in the kind of ethos and disposition it requires of scholars-providing attention to issues of power and voice and leaning into the unpredictability of the research process.
\end{abstract}

Keywords Ethnography · Volunteering · Development · Qualitative methods · Positionality

Alice Chadwick, Bianca Fadel and Chris Millora have contributed equally to this paper; therefore, author names are listed alphabetically.

\author{
Chris Millora \\ c.millora@uea.ac.uk \\ Alice Chadwick \\ amc99@bath.ac.uk \\ Bianca Fadel \\ bianca.1.fadel@northumbria.ac.uk \\ University of Bath, Bath, UK \\ 2 Northumbria University, Newcastle upon Tyne, UK \\ 3 University of East Anglia, Norwich, UK
}

\section{Introduction}

Ethnographic research has long been employed in third sector and nonprofit studies to gain highly contextual insights into the everyday and complex understandings and practices of various actors and institutions. In this paper, we move beyond a description of ethnography as a methodology and delineate what it was about the ethnographic approach that enabled us to shape research inquiries, gather and analyse data and disseminate findings in policy and practice spaces. We explore how ethnography can help us understand the links between volunteering and development, particularly when volunteering is 'utilised' as a tool for achieving often pre-defined development outcomes. Our focus here is on volunteering carried out by those within their own country or community, drawing attention to where most volunteering within development happens. By encouraging an 'endogenous lens' (c.f. Butcher \& Einolf, 2017), ethnography compelled us to refocus our gaze into local experiences, ideologies and practices of actors involved in volunteering and how these are shaped by economic, political and social forces. Ethnography can expand and problematise dominant (and seemingly normative) understandings of the links between volunteering and development by highlighting issues of power and politics in their conceptualisation and application. For third sector research more broadly, this shows how an ethnographic orientation can help deconstruct taken-for-granted concepts-such as 'volunteering' and 'development' - by shedding light on the entanglements between people, organisations and processes that make up the sector.

We start this article with a brief review of ethnography as a methodology with reference to how the approach has been employed within third sector research. The following 
sections draw from our own ethnographies of volunteering and development in the so-called Global South. ${ }^{1} \mathrm{We}$, Alice, Bianca and Chris have conducted ethnographic research in communities in Sierra Leone, Burundi and the Philippines, respectively. We discuss identity and positionality of ethnographers, local understandings of volunteering and development, and ethnography's contributions and limitations in policy and practice.

\section{Ethnography: Review and Critiques}

Ethnography is here understood as a qualitative research practice 'grounded in a commitment to first-hand experience and exploration of a particular social or cultural setting on the basis of (though not exclusively by) participant observation' (Atkinson et al., 2001, p. 4). Its premise is rooted in the importance of 'sustained social contact' as a means of respectfully representing human experience and the context where it takes place (Willis \& Trondman, 2002, p. 394). Researchers rely on their own observations over time alongside what people tell them. Ethnography places 'specific encounters, events and understandings into fuller, more meaningful context' (Tedlock, 2000, p. 165) considering historical, economic and political dimensions. This allows the ethnographer to understand people's experiences and perceptions of volunteering and how they interact with 'development' in a contextually contingent manner. Ethnography is a research process that produces a research 'product' (Bryman, 2004), generating 'thick descriptions' of social phenomenon (Geertz, 1973).

Various approaches to ethnography have developed over time (see Atkinson et al., 2001; Hammersley \& Atkinson, 2007). So-called traditional ethnographies in the early twentieth century had roots in Western anthropological study of 'exotic' and distant cultures through long-term engagement. More contemporary approaches tend to move away from such an approach and focus on 'a particular work locale or social institution' (Hammersley, 2006, p. 4) or 'institutionalised micro-social settings' (Maginn, 2007, p. 32). Within the broad field of the 'third sector', these settings could range from international aid agencies and grassroots volunteer organisations (see Banerjea, 2011; Mosse, 2011; Shachar, 2014; Wig, 2016) to intra-organisational relationships (Mazzei, 2017); social movements (Roca, 2007); and poverty alleviation (Bloom \& Kilgore, 2003). Additionally, the roles of ethnography in policymaking, public engagement and social change have been

\footnotetext{
1 The term 'Global South' in this article refers to areas geographically located mainly outside Europe and North America, but we also acknowledge the colonial history and the power inequities that contribute to perpetuate North-South divides.
}

increasingly recognised through approaches such as public ethnography, which seeks to reach non-academic audiences (Vannini \& Mosher, 2013); applied ethnography developed for policy-making and practice (Chambers, 2000); and critical ethnography which aims to reveal/challenge inequalities (Madison, 2019).

Ethnographic research, however, is not without its critiques. The history of ethnography as a means of discovering the 'other' is tied up with racist colonial approaches to human subjects within anthropology. This has led to critiques of the use of the research method within formerly colonised societies (Nyamnjoh, 2012) and compels researchers to engage with the politics of knowledge production. Additionally, the 'crisis of representation' (Denzin \& Lincoln, 1998, p. 19) requires ethnographers to be continually aware of their own biases and assumptions (Hammersley \& Atkinson, 2007). As 'ethnographic truths are... inherently partial - committed and incomplete' (Clifford, 1986, p. 7), ethnographers need to acknowledge and reflect on their positionality, power and privilege. Connected to positionality is the importance of relationships that are developed during ethnographic fieldwork and the overlapping identities assumed by researchers in this process.

\section{Ethnographers' Multiple Roles and Identities}

Our personal motivations towards researching volunteering were influenced by our previous experiences as volunteers and development workers. Ethnography compelled us to make these personal experiences visible instead of hidden in the research process. Despite not being affiliated as staff in the organisations we worked with, we were embedded in the local context in various capacities, including as volunteers. Our overt position as researchers meant that we were often seen as 'specialists' by those around us. The sense of continuity that ethnography allowed had implications on the roles that we took (some inevitably) during our fieldwork and how they shifted over time.

For example, Alice and Bianca had previously volunteered in different places for the organisations they researched with in Sierra Leone and Burundi, respectively. Their previous experience offered them 'insider' perspectives of the structures and language used to describe volunteering, but it also complicated the process of shifting to an 'outsider' perspective to identify what was contextually relevant about how volunteering was being experienced in their research settings. Additionally, Alice felt her prior knowledge of some organisations and her privileged position as a white woman from the UK placed her more firmly in the category of an 'international development worker'. She embodied some of the volunteering and knowledge 
hierarchies between international, national and community levels that the development industry is embedded in.

As we took on various roles as participant observersone of which was that of a volunteer inside the organisations we were researching with-we engaged deeply with multiple positionalities and power relationships. Ethnography encourages researchers to expand our understanding of the 'field' as more than a contained space of observation. Rather, the field could be understood as a locus of action, complex everyday routines and relationships which the researcher is part of. Chris, for instance, noticed that he was often assigned the tasks of documenter and facilitator, rather than being asked to carry boxes or clean the office. He was told this was that because he was a Ph.D. studentunlike others who had no formal qualification. He also found in his research in the Philippines that volunteers and staff in the HIV/AIDS organisation held a hierarchy of knowledge: certain volunteers thought to be more knowledgeable were assigned more complex or 'prestigious' tasks. He was entangled with the power relationships and hierarchies of knowledge that he was observing.

Exploring positionality is far from a linear process. Ethnography's emphasis on reflexivity is essential in continuously shaping the research questions and analyses. Reflexivity is also key in recognising the evolving and reciprocal relationships between participants and researchers, and honest conversations about the emotional toll and psychological demands of ethnographic research are long overdue (Dodworth, 2018).

In this section, we discussed how ethnography required us to recognise our multiple identities and the 'everchanging and negotiated positionalities we assume, create and maintain in the process of fieldwork' (Millora et al., 2020). This realisation is particularly relevant in studying volunteering through development lenses as we have also been thought of as development workers. We thus understand fieldwork as a process that is not only determined by the time spent by the researcher in the 'geographical field' but rather an ongoing experience throughout the research that is also shaped by previous experiences of both researchers and participants. Building upon these considerations, we will now explore if and how ethnography enabled us to challenge the 'taken-for-granted and fixed reality' that volunteering can hold (Shachar et al., 2019, p. 247) and its relationships with development among communities we engaged with in Sierra Leone, Burundi and the Philippines.

\section{Situating Ideologies of Volunteering and Development in Context}

In our research, we spent time with different volunteer organisations and volunteers. Some organisations had partnerships with institutions in the Global North but most volunteers were local. We attended their meetings, activities and training sessions, as well as participating with volunteers in their everyday work. We combined participant observation (recorded through field notes) with different data collection methods. Alice's approach in Sierra Leone involved narrative interviews and participatory focus groups. Bianca's work in Burundi involved semistructured interviews, mapping activities and participatory group discussions, including community exchanges that emerged from her lived experience in rural settings. Chris' comparative ethnographic case study also involved semistructured interviews and documentary analysis. Although there is no one-size-fits-all when it comes to analysing ethnographic data, processing the information tends to be an iterative process that starts during fieldwork when researchers test interpretations with participants. It then continues after 'field' activities and researchers organise the dataset and identify analytical categories to capture key aspects of the data (see Hammersley \& Atkinson, 2007, pp. 158-190).

An ethnographic approach enabled Alice to explore how volunteering for young people in Sierra Leone is embedded within the social meaning of the development industry. Exploring volunteering within its social context revealed tensions between how volunteering was promoted as a means of youth empowerment and how it was shaped by the moral economy of the labour market. Young people volunteer with the hope that someone will recognise their sacrifice and potential and give them access to future opportunities, in line with broader labour market realities. These dynamics complicate the distinction between employment and volunteering.

One young man told me he had 'volunteered' for Africell (network provider), as a sim card salesperson. He said that after a month of volunteering his hard work and ability to do the job were recognised by being given a paid position. [Field Notes, 10 Jan 2020]

For many though volunteering to enhance 'employability' is not directed at the private sector but orientated purposefully inwards towards work in the development and NGO world itself. Volunteering and insecure employment was a site of 'struggle over livelihoods and futures' (Prince, 2015, p. 103). This struggle was not just instrumental for young people in Sierra Leone-it spoke to people's moral 
identity. A recurrent theme used to frame volunteering was sacrifice, while attending a weekly youth group 'the leader urged volunteers to not think about money but sacrifice yourself and your time to help others as one day someone will recognise you' [Field Notes, 30 Feb 2019]. Spending time with volunteers highlighted the importance of being connected to a moral community of people with a willingness to give. Through volunteering, young people are doing development rather than having development done to them. This is in concord with developmental aspirations for youth empowerment, but agency was orientated towards the development industry as both a source of employment and a moral community serving individual and collective sense-making functions.

Bianca's research also led to questioning dominant humanitarian and development discourses in Burundi from the perspectives of local volunteers. A young volunteer in a rural area described development ('Iterambere' in the national language Kirundi) as follows: 'in the past there were no schools in this community, so if anybody sent a written message to warn us that the whole community would be massacred, nobody would be able to read it and we would all die, now we are instructed and this would not happen' [Focus Group Discussion, 24 May 2019]. Here, development was not framed as the lack of conflict (as it is dominantly understood) but rather having the literacy skills that would allow community members to understand an alert and, consequently, survive. Bianca's ethnographic research made visible ideologies of development from local volunteers whose presence is assumed in these spaces but whose voices are often unheard. An ethnographic approach also facilitated spontaneous conversations that informed the research framework:

I was walking with one of the volunteers in her peripheral urban neighbourhood and looking at local shops. Approaching her street, she spontaneously said 'we do not need to go to town to buy everything we need, we can find it in the neighbourhood - this is development!'. [Field Notes, 10 Apr 2019]

These informal exchanges documented as field notes helped Bianca approach the research questions through lenses that take local agency and belonging into consideration. This allowed her work to account for volunteers' everyday experiences in dealing with different levels of vulnerabilities. Her lived experience with volunteers in Burundi has also shown how wider humanitarian and development temporalities contrast with the reality of a protracted crisis. In this context, institutional divides are blurred and volunteering is effectively shaped by the mix of rhythms and routines of communities in rural and urban settings.
Finally, the ethnographic approach also allowed Chris to 'encounter' volunteering less as a discrete activity or external intervention, rather part of wider helping activities in the community. His research highlighted how 'being a volunteer' was just one of many identities that individuals 'took' or performed. Such an identity influenced and was influenced by expectations from other spaces the volunteers are part of (e.g. their homes or schools). Certain dominantly held aspects of voluntary action-for example, the notion of volunteering as unpaid-took on a different face:

...I found Tito [a youth volunteer] still waiting downstairs. He looked tired. He said he was still waiting for his incentives - around $£ 2$. He needed the money for a school project and for transportation to school the following day - 'Mama has no money to give me'. A few minutes more, Rita [NGO staff], arrived. The money was still not available - but she gave Tito 70 pence. On my way home, Tito asked me if I had 28 pence so he could ride a jeepney back home instead of walking. I gladly gave. [Field Notes, 19 Dec 2017]

For Chris, the account above illustrates how Tito, who was only 18 , was already taking on a central role in providing for his own needs (e.g. his school expenses) that his mother could not afford. Many of the youth volunteers in Chris' research were expected to provide for their households. As such, the small stipend they receive through volunteering was not considered 'extra income' but essential. These findings questioned what remuneration looks like in volunteering spaces where economic challenges are pervasive (see also Baillie Smith et al., 2020). Additionally, Rita and Chris' response in the account above was beyond the 'formal' requirements/provisions of the volunteer organisation. It was what a community member would do if another was in need. This blurs the line between organisations and the communities where they work, by showing how those who are part of organisations are also embedded in social networks that shape how volunteering operates and what it means in each context.

Taken together, ethnography's prime focus on context meant that we, as researchers, needed to ask questions that perhaps were different from those that have dominantly been asked in the literature. In our research, instead of questioning how volunteering leads to development, we were compelled to step back and ask questions such as: how do people who practise volunteering define and name volunteering? What does development mean for people in poorer communities? Recent analyses in the field of volunteering and development note the dominance of meanings and expressions often influenced by frameworks from the Global North eclipsing practices of volunteering within 
development contexts in the Global South (Butcher \& Einolf, 2017; Hazeldine \& Baillie Smith, 2015; Millora, 2020). Ethnography allowed us to complicate some of these distinctions from dominant definitions of volunteering and what form of development the practice leads to, by instead looking at how volunteering operates within organisations and is understood by individuals.

Additionally, there have been empirical studies illustrating how volunteering can counterintuitively increase inequalities especially among poorer and more vulnerable volunteers (Banerjea, 2011; Jenkins, 2009). Local ideologies of volunteering and development, such as those unearthed by Bianca, can act as counter-discourses to dominant models of volunteering and development. Chris' findings challenge normative assumptions about what volunteering means. Furthermore, because the starting point of ethnography is looking at context, volunteering can be seen as part of people's everyday lives rather than as a discrete service-delivery mechanism. Alice's findings show how volunteer activities link with other social domains-such as livelihoods and identity. Hence, ethnographic methods can tease out local ideologies of volunteering helping us to challenge assumptions within 'volunteering for development' discourse at the global level, questioning knowledge monopolies over how volunteering is transcribed into policy and practice.

\section{Ethnography and Volunteering: What Contributions to Policy and Practice?}

The field of volunteer research is often linked with practice and policy, particularly within development programmes and applied third sector research. Embedded in many discussions are questions around how research data can contribute to improvement in practices (e.g. in terms of volunteer management) or policy-making (e.g. developing national volunteering programmes). In this section, we explore the potential contribution of ethnographic research into policy and programme debates in volunteering and third sector research.

The inquiry into ethnography's role in policy-making and practice is not new and has been critically explored in areas such as aid programmes (Mosse, 2017) and literacy and development policies/programmes (Robinson-Pant, 2001; Street, 2001). A common thread in these debates is recognition that ethnography allows for an in-depth perspective on issues of power and inequalities and how certain policies are developed. In this way, ethnographic research could interrogate the process by which these policies and programmes are created in terms of who gets to decide what a 'good' or 'effective' approach means.
While we have been previously involved in volunteering (although not as ethnographers) and have donned a more evaluative lens in reflecting on our practice, we realised that we started our ethnographies with a recognition that our research might not necessarily (or directly) 'make practices better'. For instance, Chris wrote in his fieldnotes that 'rolling out HIV testing in a public area was not conducive and was not a best practice example' [Reflective note, 16 Aug 2017]. Reflecting on this and getting feedback from his supervisors, he reminded himself that his main task as an ethnographer was to document and understand how these programmes were encountered by the volunteers and not to evaluate their implementation. He realised that his tendency to think in terms of 'interventions' was partly influenced by his previous experience as a development worker in the Philippines.

Similar to what Street $(2001$, p. 2) described, we were compelled to first find out and take account of 'what was going on' in the spaces where we researched before we could attempt to suggest 'what could be changed'. The strength of the ethnographic data, therefore, was this indepth vantage point from which to view practices. We were not external evaluators with pre-set checklist and criteria. Rather, taking an 'endogenous lens' (Butcher \& Einolf, 2017), we have attempted to gain pockets of insights through our extended engagement which, when communicated with the participants, may lead to micro-changes in practices undertaken by volunteers and/or their organisations.

Yet, we also realise that the ethnographic process neither required us to completely eliminate our thoughts about 'change' and 'improvement', nor abandon our identities as development workers. As discussed earlier, the ethnographic process compelled us to explore personal histories and connections to the field instead of concealing them. However, the question of improving practice was not only our own. We realise that some of the individuals we researched with have inevitably and indirectly assigned us with roles as confidantes, advisers and evaluators (Millora, et al., 2020). For instance, Chris was asked by a staff member in the organisation he was researching with to help them develop a 'more effective' volunteer leadership training programme. Similarly, Alice and Bianca faced expectations of their research findings being used to provide 'quick-win' improvements to volunteering programmes and local development strategies.

In our research journeys, we have been invited (or at times, serendipitously have found ourselves in positions) to contribute towards broader policy and practice conversations in research projects commissioned by volunteer organisations, governments and policy-making entities. Just like Robinson-Pant's (2001) reflection on conducting an ethnographic research for an agency, we felt like our 
research data led to more questions than answers for policy-makers and practitioners. Following Rogers (2001), as ethnographers, we can make visible the multiplicity of sides and choices of a single issue but policy-makers must take sides. They need to choose a definition to make an issue 'simple' enough to warrant a feasible intervention. Our experience also highlighted the importance of language: how can we better communicate the complexity encountered through ethnographic research so that it becomes useful for a policy/programme audience? Actors in these spaces operate with different ideologies, timeframes and agendas-and there remains the question of whether and how to reconcile narratives and create spaces for these varying discourses to be discussed. In this way, continuing to engage with policy-makers and practitioners is crucial for both communicating the complexity of how volunteering and development interact in different contexts, questioning the 'fixed reality' of the concepts (Shachar et al., 2019), and challenging power structures that dictate who gets to decide what 'good practice' looks like in third sector research.

\section{Conclusion}

Our reflective accounts have shown how ethnographic data with its embeddedness in context does not accept universalised categories such as volunteering and development but rather enable an examination of their function as discourse and practice within different contexts. Because ethnography acknowledges and makes use of serendipity in the research process, ethnographers enter the field with an openness to what they may find, aware of the practice or social relations that are of interest to them but not strictly wedded to pre-defined concepts. As such, we argue that ethnography can provide more nuance to our understandings of the interface between commonly entangled concepts, for example, by highlighting diverse perspectives on volunteering ideologies and using these insights to question how volunteering policy/programmes get designed and delivered. Based on its commitment to context, embeddedness and researcher reflexivity, our experience of ethnography shows that it can offer a means to challenge research and policy discourses within the third sector, which have been traditionally skewed towards Northern perceptions and conceptualisations. Aware of the dominant discourses that already frame Southern communities in terms of deficit, we argue that ethnography can provide a framework for understanding experiences from the perspective of those involved in the practice. Moreover, the contribution of ethnography as a methodology to third sector research lies not only in the in-depth data it generates but also in the kind of ethos and disposition it requires of scholars-providing attention to issues of power and voice, and leaning into the unpredictability of research processes.

However, ethnography is not a panacea for bringing experiences from local communities, particularly in the Global South, to the fore. Ethnography's reliance upon the researcher as the means of data collection and interpretation can cause the replication of existing discourses and power dynamics, especially given the history of the methodology and the power differentials of knowledge production, often still centred on universities based in the Global North. Acknowledging this, we argue that the positionality of ethnography can become a strength through a commitment to the researcher's reflection on their role in the knowledge creation process, and open dialogue around the ethics and responsibility within relationships between researchers and participants. Furthermore, ethnography's premise in combining micro-level experiences within broader structures enables an exploration of the tensions between contextual understandings of concepts such as volunteering and development and the broader imaginaries within 'global' discourses. For volunteering, this can challenge views on what it means, where we think it happens, and who volunteers. Finally, ethnographic data can provide a framework for critiquing the structures through which policy and programmes are developed. In volunteer research, ethnography allowed us to frame our inquiries less about how volunteering leads to development but what sorts of volunteering lead to what kinds of development and for whom? For other areas of research in the third sector, ethnography may be able to provide a similar re-orientation of taken-for-granted conceptual and empirical connections.

\section{Declaration}

Conflict of interest The authors declare that they have no conflict of interest and that this manuscript has not been published or is under consideration elsewhere. All authors have contributed equally to this paper.

Open Access This article is licensed under a Creative Commons Attribution 4.0 International License, which permits use, sharing, adaptation, distribution and reproduction in any medium or format, as long as you give appropriate credit to the original author(s) and the source, provide a link to the Creative Commons licence, and indicate if changes were made. The images or other third party material in this article are included in the article's Creative Commons licence, unless indicated otherwise in a credit line to the material. If material is not included in the article's Creative Commons licence and your intended use is not permitted by statutory regulation or exceeds the permitted use, you will need to obtain permission directly from the copyright holder. To view a copy of this licence, visit http://creativecommons. org/licenses/by/4.0/. 


\section{References}

Atkinson, P., Coffey, A., Delamont, S., et al. (Eds.). (2001). Handbook of ethnography. Sage.

Baillie Smith, M., Fadel, B., O'Loghlen, A., \& Hazeldine, S. (2020). Volunteering hierarchies in the global South: Remuneration and livelihoods. VOLUNTAS: International Journal of Voluntary and Nonprofit Organizations. https://doi.org/10.1007/s11266-02000254-1

Banerjea, N. (2011). Voluntary participation and self-governance: A study of community health volunteering in Kolkata, India. Cultural Dynamics, 23, 197-218.

Bloom, L. R., \& Kilgore, D. (2003). The volunteer citizen after welfare reform in the United States: An ethnographic study of volunteerism in action. VOLUNTAS: International Journal of Voluntary and Nonprofit Organizations, 14, 431-454.

Bryman, A. (2004). Social research methods (2nd edn.). Oxford University Press.

Butcher, J., \& Einolf, C. J. (2017). Perspectives on volunteering: Voices from the south (1st ed.). Springer.

Chambers, E. (2000). Applied ethnography. In N. Denzin \& Y. Lincoln (Eds.), Handbook of qualitative research (pp. 851-869). Sage.

Clifford, J. (1986). Introduction: Partial truths. In J. Clifford \& G. E. Marcus (Eds.), Writing culture: The poetics and politics of ethnography (pp. 1-26). University of California Press.

Denzin, N., \& Lincoln, Y. (1998). Introduction: Entering the field of qualitative research. In N. Denzin \& Y. Lincoln (Eds.), Strategies of qualitative inquiry (pp. 1-34). Sage.

Dodworth, K. (2018). 'A real African woman!' Multipositionality and its effects in the field. Ethnography, 22(2), 164-183.

Geertz, C. (1973). The interpretation of cultures. Basic Books, Inc.

Hammersley, M. (2006). Ethnography: Problems and prospects. Ethnography and Education, 1, 3-14.

Hammersley, M., \& Atkinson, P. (2007). Ethnography: Principles in practice. The Cromwell Press.

Hazeldine, S., \& Baillie Smith, M. (2015). Global review on volunteering report. International Federation of Red Cross and Red Crescent Societies.

Jenkins, K. (2009). “'We have a lot of goodwill, but we still need to eat...": Valuing women's long term voluntarism in community development in Lima. VOLUNTAS: International Journal of Voluntary and Nonprofit Organizations, 20, 15-34.

Madison, S. (2019). Critical ethnography: Methods, ethics, and performance (3rd edn.). Sage.

Maginn, P. J. (2007). Towards more effective community participation in urban regeneration: The potential of collaborative planning and applied ethnography. Qualitative Research, 7, $25-43$.

Mazzei, M. (2017). Understanding difference: The importance of 'place' in the shaping of local social economies. VOLUNTAS:
International Journal of Voluntary and Nonprofit Organizations, $28,2763-2784$.

Millora, C. (2020). Volunteering practices in the 21st century. UNV and IFRC.

Millora, C., Maimunah, S., \& Still, E. (2020). Reflecting on the ethics of PhD Research in the Global South: Exploring reciprocity, reflexivity and situatedness. Acta Academica, 52(1), 67-87.

Mosse, D. (2011). Adventures in Aidland: The anthropology of professionals in international development. Berghahn Books.

Mosse, D. (2017). Is good policy unimplementable? Reflections on the ethnography of aid policy and practice. The Anthropology of Organisations, 35, 451-483.

Nyamnjoh, F. B. (2012). Blinded by sight: Divining the future of anthropology in Africa. Africa Spectrum, 47, 63-92.

Prince, R. J. (2015). Seeking incorporation? Voluntary labor and the ambiguities of work, identity, and social value in contemporary Kenya. African Studies Review, 58, 85-109.

Robinson-Pant, A. (2001). Women's literacy and health: Can an ethnographic researcher find the links? In B. Street (Ed.), Literacy and development: Ethnographic perspectives (pp. 152-170). Routledge.

Roca, B. (2007). Organizations in movement: An ethnographer in the Spanish campaign poverty zero. VOLUNTAS: International Journal of Voluntary and Nonprofit Organizations, 18, 116-134.

Rogers, A. (2001). Problematising literacy and development. In B. Street (Ed.), Literacy and development: Ethnographic perspectives (pp. 205-222). Routledge.

Shachar, I. Y. (2014). The white management of 'volunteering': Ethnographic evidence from an Israeli NGO. VOLUNTAS: International Journal of Voluntary and Nonprofit Organizations, 25, 1417-1440.

Shachar, I. Y., von Essen, J., \& Hustinx, L. (2019). Opening Up the "Black Box" of "Volunteering": On hybridization and purification in volunteering research and promotion. Administrative Theory and Praxis, 41, 245-265.

Street, B. (2001). Introduction. In B. Street (Ed.), Literacy and development: Ethnographic perspectives (pp. 2-18). London.

Tedlock, B. (2000). Ethnography and ethnographic representation. In N. Denzin \& Y. Lincoln (Eds.), The Sage handbook of qualitative research (2nd ed., pp. 455-486). Sage.

Vannini, P., \& Mosher, H. (2013). Public ethnography: An introduction to the special issue. Qualitative Research, 13, 391-401.

Wig, S. (2016). The purchase of volunteerism uses \& meanings of money in Lesotho's development sector. In R. J. Prince \& H. Brown (Eds.), Volunteer economies the politics and ethics of voluntary labour in Africa (pp. 75-95). Woodbridge.

Willis, P., \& Trondman, M. (2002). Manifesto for ethnography. Cultural Studies, 2, 394-402.

Publisher's Note Springer Nature remains neutral with regard to jurisdictional claims in published maps and institutional affiliations. 